\title{
Characteristics of dynamic response and cumulative damage life of soft rock under the high-speed railway tunnel
}

\author{
Xiang-qiu Wang ${ }^{1, a}$, Wen-xi Xie ${ }^{1, b}$, Bin Cai ${ }^{2, c}$ \\ 1. Dept. of Civil Engineering, Foshan University, Foshan,528000, China \\ 2 Guangdong Nanhai International Architectural design co., Itd \\ atongji_wxq@163.com, ${ }^{\text {bxwx14@qq.com, }{ }^{\text {c8 }} 864353786 @ q q . c o m}$
}

\begin{abstract}
keywords: tunnel of High-speed railway; soft rock under the bottom of tunnel; Dynamic characteristics; accumulative damage life
\end{abstract}

\begin{abstract}
Based on the method of nonlinear finite element, the dynamic response characteristics and fatigue life of soft rock at the bottom of the typical cross section of high speed railway are studied. The research result shows that the peak dynamic stress of the soft rock increases nonlinearly with the increase of the speed of train, and decreases nonlinearly with the increase of the depth and the strength of the soft rock. Based on the Miner accumulated damage theory, the fatigue life of the soft rock at the bottom of a high-speed railway tunnel is studied. The research has certain pragmatic value to improve our country's high-speed railway tunnel design and operation management level.
\end{abstract}

\section{Introduction}

As the experience in railway operation and researches in China were shown in[1-7], for the surrounding rock at the bottom of the high-speed railway tunnel suffer the impact of the trains' vibration, prone to fatigue damage. However, its damage life and characteristics is primarily influenced by the strength of surrounding rock at the bottom of the high-speed railway tunnel and the speed of train. Because of the history of China's high-speed railway operation is not very long, the current academic research on the fatigue damage and life characteristics of the bottom structure of high-speed railway tunnel is relatively small in the academic circle, therefore, this paper studies the dynamic response and fatigue characteristics of the surrounding rock at the bottom of the high-speed railway tunnel under the condition of different surrounding rock strength and train speed for China's current high-speed railway typical tunnel structure.

\section{Conditions of tunnel and surrounding rock}

In order to make the research results representative, a tunnel project of the Guangzhou-Wuhan express railway is chosen as the research object. The section size is shown in Figure 1, and the physical and mechanical parameters of the tunnel lining and the rail board are shown in Tab.1. The concrete intensive grade of secondary lining is C35. The concrete intensive grade of the invert filling and preliminary lining is C20. And C45of high strength concrete is selected as the material of the rail board. The concrete intensive grade of the supporting layer is C30. The depth of the tunnel is $11.2 \mathrm{~m}$. In order to analyze the influence of the surrounding rock conditions on the dynamic response of the bottom structure of the tunnel, 4 kinds of rock mass (SY1-SY4) with different strength grades were studied. The mechanical parameters of the rock mass were shown in Tab.2. 
Tab.1 Physical and mechanical parameters of lining of tunnel

\begin{tabular}{c|c|c|c|c}
\hline $\begin{array}{c}\text { parameters } \\
\text { type }\end{array}$ & $\mathrm{E} / \mathrm{MPa}$ & $f_{c} / \mathrm{MPa}$ & $\mu$ & $\gamma / \mathrm{kN} / \mathrm{m}^{3}$ \\
\hline Secondary Lining & 31500 & 17.5 & 0.2 & 26.3 \\
\hline Preliminary Lining & 28000 & 12.5 & 0.2 & 23.0 \\
\hline Invert & 28000 & 12.5 & 0.2 & 23.0 \\
\hline Invert Filling (C35) & 30000 & 15.0 & 0.2 & 25.0 \\
\hline Rail Board & 35000 & 21.5 & 0.2 & 27.0 \\
\hline
\end{tabular}

Tab.2 parameters of different intensity soft rock

\begin{tabular}{|c|c|c|c|c|c|c|}
\hline $\begin{array}{l}\text { parameters } \\
\text { type }\end{array}$ & $\mathrm{E} / \mathrm{MPa}$ & $f_{c} / \mathrm{MPa}$ & $\mathrm{C} / \mathrm{KPa}$ & $\varphi /\left({ }^{\circ}\right)$ & $\mu$ & $\gamma_{/ \mathrm{kN} / \mathrm{m}^{3}}$ \\
\hline SY1 & 102.73 & 1.12 & 204.04 & 29.6 & 0.35 & 20.0 \\
\hline SY2 & 206.00 & 2.03 & 251.31 & 46.5 & 0.35 & 20.0 \\
\hline SY3 & 377.9 & 3.95 & 398.01 & 51.5 & 0.35 & 20.0 \\
\hline SY4 & 541.66 & 5.01 & 561.38 & 51.7 & 0.35 & 20.0 \\
\hline
\end{tabular}

\section{Analysis Model of 3D-FEM}

A dynamic analysis model of the tunnel as shown in figure 1 and the wall rock is established. A three-dimensional dynamic FEM model is established based on the MIDAS GTS NX a large geotechnical nonlinear FEM analysis platform. A 3-D dynamic FEM analysis model is built around the center of the double line tunnel section of High-speed rail. The left and right boundary of the model is extended from the left and right edge of the tunnel lining to the base of the $55 \mathrm{~m}$. The bottom boundary of the model is $40 \mathrm{~m}$ lower than the bottom of tunnel lining, and the top boundary of the model is the natural ground. The yield criterion of the wall rock is Drucker-Prager criterion. The solid elements are used as the models of the lining structure, the track board, the invert and the invert filling. The analysis model consists of 45465 elements. The FEM model is shown as Fig. 1.
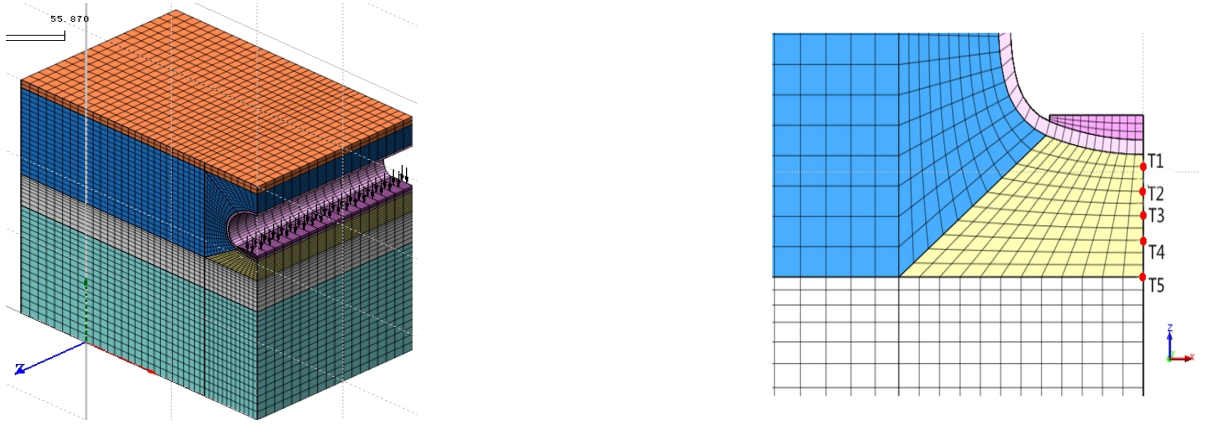

Fig.1 3-D FEM model of the tunnel

\section{Boundary conditions of dynamic analysis}

In consideration of the tunnel of the Guangzhou-Wuhan express railway is a semi-infinite underground structure and the experience of relevant research work, the dynamic response of the tunnel structure in semi-infinite space can be simulated by setting the appropriate artificial dynamic analysis in order to simplify the analysis process. According to the mechanical behavior of wall 
rock, the artificial viscoelastic boundary supports are used, that is, curved springs are applied to the boundary of the model, the spring stiffness and the damping constant are calculated as follows [8]. vertical foundation coefficient:

$$
k_{v}=k_{v 0}\left(\frac{B_{v}}{30}\right)^{-3 / 4}
$$

horizontal foundation coefficient:

$$
k_{h}=k_{h 0}\left(\frac{B_{h}}{30}\right)^{-3 / 4}
$$

in which, $k_{v 0}=\frac{1}{30} \alpha E=k_{h 0}, \quad B_{v}=\sqrt{A_{v}}, \quad B_{h}=\sqrt{A_{h}}$

Where: $A_{v}$ - the aera of vertical boundary.

$A_{h}$ - the aera of horizontal boundary .

$E$ - the elastic modulus of the wall rock, $\mathrm{KPa}$;

$\alpha$-Correction factor, depends on the nature of the wall rock.

damping constant:

$$
\begin{aligned}
& C_{p}=\rho \sqrt{\frac{\lambda+2 G}{\rho}} \\
& \lambda=\frac{\mu E}{(1+\mu)(1-2 \mu)} \\
& G=\frac{E}{2(1+\mu)}
\end{aligned}
$$

Where: $\rho$-the density of the wall rock, $\mathrm{kN} / \mathrm{m}^{3}$;

$\mu$-Poisson's ratio;

\section{Dynamic response of soft rock under the bottom of tunnel}

Dynamic response analysis are conducted in 4 different rail speed and 4 different surrounding rock conditions with the dynamic analysis model is shown in figure 1. The time-history curve of dynamic loading under different rail speeds reference literature [8]. 5 feature points are chosen as the research objects, whose vertical distance from the bottom of the invert is $0.5 \mathrm{~m}, 1.5 \mathrm{~m}, 2.5 \mathrm{~m}$, $3.5 \mathrm{~m}$ and $5 \mathrm{~m}\left(\mathrm{~T}_{1}, \mathrm{~T}_{2}, \mathrm{~T}_{3}, \mathrm{~T}_{4}, \mathrm{~T}_{5}\right)$ 。 The dynamic responses of the wall rock at the bottom of the tunnel in different analysis cases are shown in Fig. 2.

In Fig.2, it can be found out that the peak vertical dynamic stress increases with the increase of soft rock strength, but decreases gradually with the increase of depth. Under the same soft rock strength level, the peak vertical dynamic stress and amplitude of each feature point increases with the increase of rail speed, but decreases with the increase of depth. 


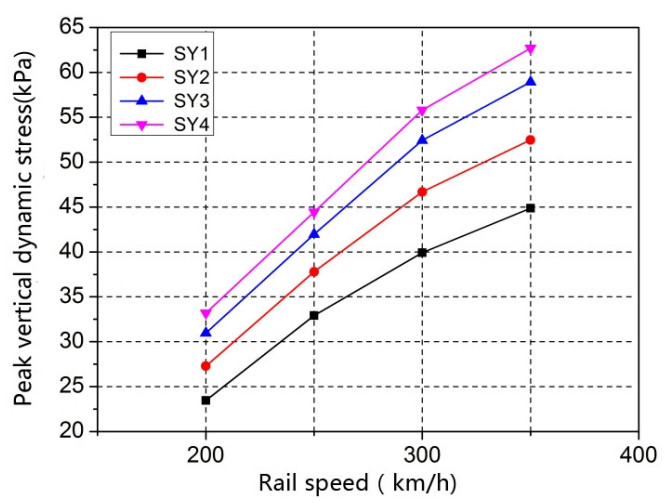

a) the point of $\mathrm{T} 1$

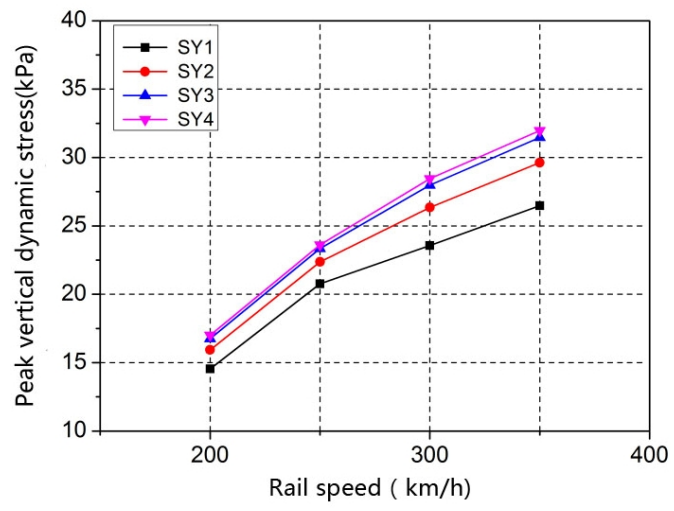

c) the point of $\mathrm{T} 4$

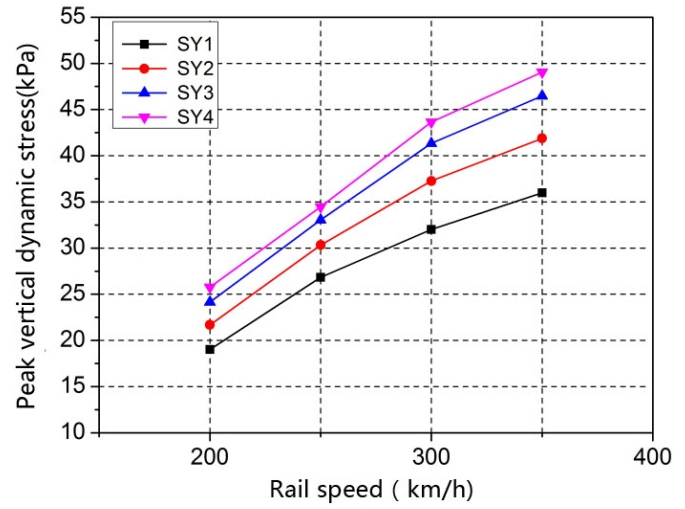

b) the point of $\mathrm{T} 21.5 \mathrm{~m}$

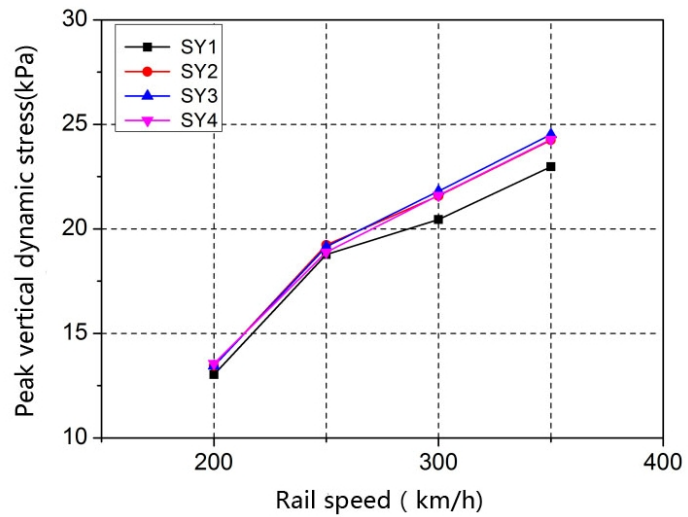

d) the point of $\mathrm{T} 5$

Fig. 2 vertical dynamic stress on the different points under different speed

\section{Fatigue life analysis for soft rock}

Assuming that 100 pairs of trains pass by per day on average during the operation, each train has 16 formations. If the damage variable of the tunnel structure and basement wall rock reaches 0.95 , the structure is considered failure.

In order to simplify the calculation and consider the most unfavorable conditions for the fatigue life of soft rock, a single two-way train passing through the tunnel at the same time is regarded as a load cycle in the prediction of the fatigue life of the base rock, based on that, the short-term and long-term fatigue life of the soft rock is calculated.

From Miner accumulated damage theory and soft $\operatorname{rock} S-\lg N$ fatigue characteristic curve, the damage parameter of soft rock in a load cycle can be defined. The value and calculation method of $N_{f}$ is shown in Literature [8].

$$
D_{1}=\frac{1}{N_{f}}
$$

The Fatigue life is calculated according to the following formula:

$$
T_{p}=\frac{0.95}{D_{1}} \times \frac{1}{365 \times 100}
$$

At present, China's high-speed railway operating speed is about $300 \mathrm{~km} / \mathrm{h}$. The fatigue life calculation results of soft rock with different strength at this speed the relationship between the strength of soft-rock and the predicted fatigue life was obtained by using quadric curve with 3 
parameters:

$$
T_{p}=9.41 f_{c m}^{2}-21.3 f_{c m}+25.95
$$

When the base of the tunnel is in soft rock of low intensity or soft soil area, it is necessary to strengthen the base of a certain depth to meet its anti-fatigue design requirements.

\section{Acknowledgements}

This work was financially supported by the project of National Natural Science Fund(51278121) and the major project of Guangdong province (2014KTSCX155).

\section{References}

[1] Zhu Wanting,Li Lanqin. Base Diseases in Tunnels and Their Cause Analysis [J],Modern Tunnelling Technology,2001,38(5):42-44.

[2] Chen Zuhua,Zhou Yinghua. Comprehensive Renovation of the Existing Tunnel Bed Disease [J]. Railway Standard Design, 2002, 6(4):36-37.

[3] Shi Chenghua,Peng Limin,Huang Juan. Study on Mechanism and Treatment Measures of Foundation Base Disease in Railway Tunnel [J]. China Railway Science, 2005, 26(4):62-67.

[4] Cheng Xuewu,Dong Jing. Analyses of the Cause for the Fracture of Monolithic Concrete Bed in Tunnel and Treatment Measures [J]. Journal of Railway Engineering Society, 2009, 128 (5 ): 64-68. [5] Ding Zude. Dynamic Properties of Soft Rock and the Safety of Base Structure of High-speed Railway Tunnels [D]. Central South University, 2012.

[6] Forrest J A, Hunt H E M. Ground vibration generated by trains in underground tunnels [J]. Journal of Sound and Vibration, 2006, 294(4): 706-736.

[7] Gardian W, Stuit H G. Modeling of soil vibrations from railway tunnels [J]. Journal of Sound and Vibration, 2003, 267(3):605-619.

[8]Cai Bin. Study on the Characteristics of Dynamic and Fatigue Damage of Soft Rock-mass for Basement of High Speed Railway's Tunnel [D]. Guangdong University of Technology,2015. 